\title{
SOCIEDADES ECONÓMICAS E INGENIEROS DE MONTES EN FILIPINAS. SOBRE EL APROVECHAMIENTO FORESTAL DURANTE EL PERÍODO DE ADMINISTRACIÓN ESPAÑOLA, 1775-1898*
}

POR

\section{SUSANA PINAR}

Universidad de California-Irvine

Centro de Estudios Históricos, CSIC

\begin{abstract}
En este artículo se analiza el papel de las sociedades económicas y del posterior cuerpo de Ingenieros de Montes en relación a la explotación forestal filipina, desde el último cuarto del siglo XVIII hasta el final de la administración española.

Desde su perspectiva comercial, carente de conciencia conservacionista, la necesidad de racionalizar la explotación de los bosques fue cobrando fuerza a lo largo del siglo XIX, si bien el mantenimiento de prácticas inadecuadas y un escaso apoyo institucional a nivel económico y de personal hicieron infructuosos los esfuerzos de sus responsables.
\end{abstract}

\section{INTRODUCCIÓN}

El desarrollo científico de las Filipinas y más concretamente el conocimiento de sus recursos naturales, estuvo mediatizado por la posición de las Islas en el entramado colonial español. Como colonia satélite de la de Nueva España ${ }^{1}$, a la que permaneció ligada económicamente a través del Galeón de Acapulco, quedó al margen de las corrientes científicas imperantes, las cuales nunca alcanzaron en las Islas el vigor logrado, por ejemplo, al otro lado del Pacífico.

SIGLAS UTILIZADAS:

AGI: Archivo General de Indias, Sevilla.

AMS: Archivo del Museo Naval, Madrid.

* Este artículo se hizo gracias a una beca del programa Fulbright/MEC F97 02883722

1 V. CASAls Costa,. «Montes e ingenieros en Ultramar. Las ideas sobre la protección del bosque en Cuba y Filipinas durante el siglo XIX». J.L. PESET, (coord), Ciencia, vida y Espacio en Iberoamérica, Madrid, III Vols., CSIC, 1989, vol. III, pp. 357-358. 
Con motivo del propio proceso de colonización filipina, los primeros estudios de índole naturalista fueron llevados a cabo por los religiosos desplazados al Archipiélago en misión evangelizadora, destacando, sin profundizar en la labor de cada uno de ellos, los de los Padres: Ignacio Mercado, Francisco Ignacio Alsina, Domingo Vidal, Celestino Fernández Villar, Manuel Blanco, etc, junto a los de los alemanes al servicio de España Camellius y S.J. Clain, entre otros ${ }^{2}$.

Con respecto al aprovechamiento de los bosques y las tierras de labor, las Leyes de Indias incluyeron diversas disposiciones en favor de los indígenas otorgándoles derechos a la hora de la corta de madera para uso personal, si bien ésta debía realizarse sin causar daño alguno que pudiera impedir el crecimiento y la multiplicación de los árboles ${ }^{3}$; de igual manera, se favoreció al indígena en la posesión usufructuaria de la tierra, estableciendo la obligación de proceder al desmonte de los terrenos baldíos a corto plazo, superado el cual, si no se procedía a su cultivo, se invalidaban los derechos adquiridos sobre las tierras ${ }^{4} \mathrm{y}$, más tarde, se limitó los de los terrenos adyacentes a los pueblos ${ }^{5}$; normativas todas ellas dirigidas a la potenciación del desarrollo agrícola. En este contexto, la peor faz de la actividad religiosa fue el excesivo celo a la hora de defender los derechos de los indígenas ${ }^{6}$, frenando la agricultura por las trabas legales interpuestas a los europeos, al tiempo que se fomentaba el desarrollo latifundista, especialmente, en favor de sí mismos. Consecuentemente, dicha legislación unida a un lento proceso de privatización de la tierra y a un ínfimo desarrollo colonial, permitió los usos fraudulentos de la propiedad comunal y las talas abusivas para la construcción naval, manteniendo, por otra parte y durante muy largos años, inadecuadas prácticas agrícolas.

La erradicación de los males no se logró durante la administración española de las Islas, si bien se promovieron acciones en ese sentido. Al final del siglo XVIII, las instituciones implicadas no mostraban aún una conciencia conservadora hacia el medio ambiente, estando mayormente enfocadas al aprovechamiento

2 Véase entre otros: A. BARREIRo e I. BolivAR, Discurso leído en el acto de su recepción por P. Agustín J. Barreiro y contestación del académico D. Ignacio Bolivar el día de mayo de 1928. Características de la fauna y flora de Filipinas y labor española en el estudio de las mismas. Madrid, Real Academia de Ciencias Exactas, Físicas y Naturales, 1928.

3 V. CASAls Costa, [1], p. 367.

4 Ley 14, título 17, libro 4, (1594), según la Recopilación de las leyes de los reynos de Indias, mandadas imprimir y publicar por S.M. Católica del Rey D. Carlos III, Madrid, Imprenta vda. De Joachin Ibarra, $4^{\text {a }}$ impresión, 1731.

5 S. VIDAL, El ramo de montes en las islas Filipinas. Madrid, Aribau y Cía, 1874, p. 65; también: V. CASALS COSTA, «Del cultivo de los árboles a las leyes de la espesura». Manuel LUCENA GIRALDO (ed.), El Bosque Ilustrado. Estudios sobre la política forestal española en América, Madrid, Icona-Instituto de la ingeniería de España, 1991, pp. 63-89, ver p. 74.

6 V. CASAls COSTA, [1], pp. 360-362 y J. GÓMEZ MENDOZA, Ciencia y política de los montes españoles (1848-1936). Madrid, Icona, Clásicos, 1992, p. 21; véase también: V. CASALS CosTA, [5], pp. 63-89.

\section{R. I., $1999, \mathrm{n}^{\circ} 216$}


comercial de los recursos naturales, en especial, hacia la modernización de las técnicas agrícolas con el objeto de mejorar la producción de determinados cultivos y lograr la introducción de otros, así como hacia la reivindicación de los productos autóctonos frente al resto de las mercaderías asiáticas. En este marco, esencialmente comercial, se han de encuadrar las fundaciones de instituciones como la Sociedad Económica de Amigos del País de Manila o la Real Compañía de Filipinas, ambas erigidas durante el último cuarto del siglo XVIII con objeto de establecer un comercio propio al margen del efectuado a través del Galeón de Acapulco y sostenido gracias al reconocimiento, inventariado y aprovechamiento de las riquezas naturales filipinas?.

A mediados del siglo XIX se creó el Cuerpo de Ingenieros de Montes, instituyéndose pocos años después la primera Inspección de Montes en las Filipinas con motivo del nuevo auge de las Islas derivado de la necesidad de maderas para la industria naval y de su comercio. Sus objetivos fueron el inventariado, la explotación racional y la conservación de los montes; sin embargo, sus resultados no estuvieron a la altura de lo que habían planeado como consecuencia de la escasa ayuda por parte del Estado, principalmente con respecto a la falta de personal facultativo y a la persistencia de abusos y técnicas tradicionales de difícil destierro.

Legislativamente, se mantuvieron las ordenanzas de las antiguas Leyes de Indias a fin de preservar los derechos y privilegios obtenidos por los indígenas, en tanto que se transformaban sus necesidades y costumbres hasta llegar a la abolición de prácticas incompatibles con la conservación del arbolado. Dichas ordenanzas fueron modificadas progresivamente y ampliadas con las disposiciones aplicables a los montes de Indias y Provincias de Ultramar dictadas bajo la jurisdicción de la Marina, las leyes y reglamento de la Administración Forestal fundada en 1853, así como por la normativa impuesta diez años después por el recién creado Ministerio de Ultramar, marcando un hito legislativo con el «Reglamento Definitivo para el Servicio del Ramo de Montes en el Archipiélago Filipino» de 1873, reafirmado en 1884, en el que se regulaba la explotación de los bosques al modo de los procedimientos seguidos por los ingleses y holandeses en Birmania y $\mathrm{Java}^{8}$.

En definitiva, he querido mostrar cómo durante el final del siglo XVIII el acercamiento a la naturaleza circundante se realizó principalmente desde un punto de vista comercial, si bien fue también el período en el que florecieron los estudios de clasificación biológica, paso previo necesario para cualquier labor de conservación posterior. En este sentido, sólo a medidos del nuevo siglo surgió una institución de carácter conservacionista, consciente del deterioro que estaba

7 M.L. Rodríguez Baena, La Sociedad Económica de Amigos del País de Manila en el siglo XVIII, Sevilla, E.E.H.A, 1966.

8 Dicho documento puede consultarse íntegro, junto con un catálogo legislativo, en: G. de ARANDA, (1995). La administración forestal y los montes de Ultramar durante el siglo XIX, Madrid, Icona, Clásicos, 1995. 
sufriendo las Filipinas. El Cuerpo de Ingenieros de Montes realizó una importante labor en diversos sectores, entre los que destacó el aprovechamiento forestal. La pretensión de nuestro estudio es dar un pequeño esbozo sobre todos estos puntos.

\section{LOS RECURSOS FILIPINOS COMO FUENTE DE RIQUEZA COLONIAL}

La Sociedad Económica de Amigos del País de Manila fue fundada en 1781 bajo la dirección de Ciriaco González Carvajal, quien permaneció en el cargo durante sus cinco primeros años de existencia, sin duda los más fructíferos, y fue seguido hasta su disolución en 1797 por Francisco Javier Moreno. Exentos del apoyo institucional debido, a los pocos años de su fundación la Sociedad Económica entró en decadencia en detrimento del desarrollo científico y la mejora económica de las Islas, perdiendo la oportunidad de haberse erigido como uno de los más activos promotores de las riquezas y productos del país, así como de la potenciación de su industria y de la educación de sus ciudadanos.

«Promover, por todos los medios posibles, la agricultura, la industria y el comercio» ${ }^{9}$, fue el objetivo de la Sociedad desde su fundación, razón por lo que ya en sus primeras Actas ${ }^{10}$, publicadas en 1782, se fijaron y delinearon los campos de actuación de las cinco comisiones claves creadas para el incremento de diversos aspectos de la economía colonial, definidas como siguen: 1. Historia Natural; 2. Agricultura y Economía Rústica; 3. Fábricas y Manufacturas; 4. Prospección del Comercio Interno, y 5. Plan de Desarrollo y Difusión de la Enseñanza de Técnicas y Manufacturas Textiles. En las Actas, junto al trazado de las comisiones, se solicitaba de sus socios cuenta exacta de los progresos realizados en cada área, la consulta y la elaboración de dictámenes acerca de distintas materias de interés - como la cría de gusanos de seda, el comercio, el añil, etc.-, fijándose, para incentivar su estudio, la adjudicación de premios a las mejores producciones.

Como puede vislumbrarse por el epígrafe, ninguna de las comisiones fue ajena al medio natural, sin embargo las dos primeras se hallaban directamente inmersas en su ámbito. De hecho, la comisión de «Historia Natural» fue considerada la base teórica de las restantes, pues «la riqueza y fecundidad de la tierra se encuentra en su superficie y en su seno para dar al Comercio, y a la Medicina mil objetos utiles, y a la curiosidad otros agradables, en executar el placer y la admiración » ${ }^{11}$. En este mismo sentido, se reconoció que los recursos naturales de las Filipinas eran muy numerosos, pero se hallaban más intuidos que conocidos y

9 M.L. Rodríguez BAENA, [7], p. 44.

10 Actas de la Sociedad Económica de las Islas Filipinas. Manila, 11 de junio de 1782, AGI, Filipinas, leg. 593, n 53.

11 Actas, Manila, 11 de junio de 1782, AGI, Filipinas, Estado, leg. 593, n 53.

R. I., $1999, \mathrm{n}^{\circ} 216$ 
aunque ofrecían grandes posibilidades, el retraso sufrido en su conocimiento con respecto al resto de los países y la falta de personal cualificado que pudiera llevar a efecto dicha tarea, habían mermado su explotación, siendo uno de los principales problemas que debían ser solventados.

La Comisión de «Agricultura y Economía Rústica», se centró en: la explotación de la tintura del añil, especialmente en todo lo concerniente al perfeccionamiento del método guatemalteco de obtención del tinte; la canela, que se daba de forma natural en Mindanao pero presentaba aún problemas por exceso de mucílago, provocando su depreciación en Acapulco en favor de la importada desde la China; el clavo y la nuez moscada, especias que se pensaba podían ser obtenidas fácilmente a través del sultanato de Simbuey para luego proceder a la introducción de su cultivo en el Archipiélago, como se había hecho ya con la pimienta, la cual aún presentaba algunos problemas a la hora de su multiplicación; contemplándose, igualmente, como subceptibles de mejora el sector apícola, el del cultivo de la seda y el del algodón.

Sin embargo y a pesar de tan buenos proyectos, la Sociedad Económica no obtuvo grandes rendimientos, consecuencia, por un lado, de la gran desidia de sus miembros - preocupados más por el reparto de los fondos del Galeón que por el fomento nacional-, que dejaron de asistir a las juntas de la Sociedad al poco de su erección, como señalaba su director al ministro español José de Gálvez en carta del 5 de junio de 1785: «De los otros Socios no puedo decir á V.E. otra cosa, sino que no quieren asistir á las Juntas, y que las más de las tardes nos vemos solos en ellas el Consultante, Censor, Secretario, y Tesorero; y apenas una, ú otra tarde concurren uno, ó dos más» ${ }^{12}$; y, por otro, a una fuerte disensión a nivel institucional entre la Sociedad y el Consulado de Comercio y, a nivel personal, entre González Carvajal y el gobernador general de las Islas, José Basco y Vargas, quien por otra parte había sido uno de los promotores de la propia Sociedad. El freno que supuso ambas disputas condujo a un fuerte desprestigio de las actividades de la Sociedad cara al público, como puede apreciarse en el relato que Jagor hace de su viaje por las Islas, en el que son acusados de no hacer nada productivo y de «no destinar cantidad alguna al fomento de la riqueza pública, a pesar de ser éste el objetivo con que la Sociedad fue creada» ${ }^{13}$.

Con respecto al primer punto, el Consulado de Comercio de Manila fundado en 1769, englobó en sí mismo todos los intereses que hicieron posible el mantenimiento de la exclusividad del comercio con Nueva España ${ }^{14}$, oponiéndose

12 Consulta de González Carvajal a J. Gálvez, Manila, 20 de julio de 1785, AGI, Filipinas, Estado, leg. 691. $\mathrm{n}^{\circ} 2$.

13 F. JAGOR, Viaje por Filipinas, Madrid, Aribau y Cía, 1875, pp. 323-324.

14 W.E. CHeOng, «The Decline of Manila as the Spanish Entrepôt in the Far East (17851826): Its Impact on the Pattern of Southeast Asian Trade», Journal of Southeast Asian Studies, 2(2), 1971, pp. 142-158; M.L. Díaz-TREChuelo SPINOLA, «Dos nuevos derroteros del Galeón de Manila 1730-1773», Anuario de Estudios Americanos, XIII, 1961, pp. 1-83; M.L. DíAZ-TRECHUELO 
siempre al reparto de los fondos del Galeón, solicitud reiteradamente hecha por la Sociedad y por la Real Compañía de Filipinas para poder llevar a efecto una mejora de la agricultura, la industria y las artes. En este sentido y como un ejemplo más, el 31 de mayo de 1783 González Carvajal propuso a Gálvez que se procediera a la revisión de la adjudicación de las partidas del Galeón, suprimiendo aquellas innecesarias o que fomentasen las actitudes relajadas y exentas de un beneficio real para el conjunto de la colonia, incentivando por contra a los que «promoviesen y estableciesen fabricas de manufacturas utiles, á los que tuviesen laboratorios de añil: á los que tuviesen Barcos para el trafico interior, y exterior de las Islas, á los que hiciesen alguna señalada accion contra los enemigos... Y de lo que quedase, despues de atendidos estos objetos, se aplicase un fondo competente á la Sociedad para qe. por sí, y sin estrecharse a los límites de dár solamente luzes, pásase por si misma á executar sus pensamientos en fomento de las Islas» ${ }^{15}$.

A pesar de estas y otras solicitudes, el monopolio del Galeón pervivió hasta 1813, siempre bajo el auspicio de la primera institución, reconociéndose como uno de los principales males económicos al favorecer la especulación e incrementar el poder latifundista; por dejar el pequeño comercio en manos de la población china, quienes entorpecieron la circulación del dinero, siendo objeto de repetidas matanzas; por abandonar la agricultura y por acentuar las diferencias sociales y oficializar la corrupción. Una y otra vez, los logros económicos a corto plazo fueron la causa por la que se dejó de potenciar la agricultura y de apoyar los productos coloniales, comerciando, en su lugar, con las mercaderías de la China de beneficios más inmediatos. Con respecto al segundo punto, las dos autoridades con mayor influjo en el desarrollo de las Islas, José Basco y Vargas y González Carvajal, se encontraban enfrentadas desde que en julio de 1784, el segundo fuese nombrado Intendente del Ejército y Real Hacienda ${ }^{16}$, puesto que había sido creado para la descentralización de la administración de las Islas, recortando en cierta medida el poder del gobernador. En la lucha de competencias, Basco y Vargas hizo todo lo posible para limitar las prerrogativas concedidas en materia de justicia y policía en las distintas provincias a González Carvajal, autoridad necesaria desde el punto de vista del nuevo intendente para poder llevar a término «el objetivo de este nuevo establecimiento, ó las causales, que se expresan, son la necesidad, que tienen estas Islas, según se halla S.M. justamente persuadido, de un Intendente, que contribuya al fomento de la agricultura, población, y

SPINOLA, «El comercio de Filipinas durante la segunda mitad del siglo XVIII». Revista de Indias, 93-94, 1963, pp. 463-485.

15 Carta de González Carvajal a José de Gálvez, Manila, 31 de mayo de 1783, AGI, Filipinas, Estado, leg. 729 , doc. 2.

16 Véase la Real Orden del 26 de julio de 1784 por la que se nombra a González Carvajal Intendente en: AMN, ms. 2187, ff. 1-3.

R. I., $1999, \mathrm{n}^{\circ} 216$ 
comercio, y á poner a mejor orden los Ramos de Real Hacienda» ${ }^{17}$; a sus ojos, tales recortes limitaban sus funciones a las de mero ayudante del gobernador.

La literatura sobre tales disensiones es abundante pero no nos vamos a extender en este tema, sólo haremos hincapié en la ocasión que se perdió de dar un giro económico en las Islas. Así, finalmente y en buena parte como consecuencia de sus desavenencias con el gobernador, González Carvajal decidió abandonar la Intendencia y marchar a México ${ }^{18}$. Del mismo modo, algunas de las figuras que habían iniciado una interesante labor como naturalistas al servicio de la Sociedad o bajo la protección de su director, vieron frustrados sus estudios de historia natural. Entre éstos mencionaré únicamente a José García Armenteros y a Francisco Noroña, aunque otros muchos, en su mayoría religiosos, contribuyeron con su labor durante los años en que permaneció en activo la Sociedad ${ }^{19}$.

José García Armenteros fue criado en la Intendencia de Marina de la Isla de León; cursó estudios de física, astronomía, historia natural y lenguas modernas; en 1772 fue contador en la fragata Venus, estableciéndose luego en Filipinas durante el mandato del gobernador Simón de Anda; más tarde sirvió en la Alcaldía Mayor de Iloilo y, posteriormente, fue nombrado secretario de la Sociedad Económica ${ }^{20}$, para la que elaboró diversos estudios relacionados con la historia natural de las Islas: Discurso sobre los medios eficaces de verificar la siembra del añil, el plantío de moreras y la cría de abejas en colmenas (1784), así como varias memorias sobre diferentes asuntos de interés como eran la brea fósil, las mareas, los nidos de golondrina comestibles, el magnetismo o la cartografía, y un Discurso sobre la utilidad del comercio de Filipinas a los reinos inmediatos de este archipiélago y los medios de establecerlo y practicarlo, ejecutado en 1786 y premiado por la Sociedad ${ }^{21}$. Del mismo modo, Armenteros trabó contacto con Alejandro Malaspina (1754-1794), el Almirante que realizara un viaje de circunnavegación bajo la Corona Española, quien llegó a proponer a las autoridades filipinas que éste lo acompañase durante la etapa de expedición del Archipiélago $^{22}$. Por otra parte, Malaspina incorporó en sus trabajos algunos de los argumentos que el secretario de la Sociedad había utilizado en su Discurso sobre la utilidad del comercio de Filipinas, copiando íntegramente la memoria de Armenteros, Observaciones sobre el estado político y económico de las Islas Filipi-

17 Carta de González Carvajal a José de Gálvez, Manila 19 de diciembre de 1785, AGI, Filipinas, Estado, leg. 691, doc. 65.

18 M.L. RodríGuez BAENA, [7], p. 173.

19 Se puede consultar la lista de premios y gratificaciones otorgandos en enero de 1786 por la Sociedad Económica en: M.L., RodRíGUEZ BAENA, [7], pp. 203-204.

20 Consulta de Ciriaco González Carvajal a José de Gálvez, Manila, 11 de julio de 1785. AGI, Filipinas, leg. 785 , n. 4.

21 Las citadas memorias pueden consultarse en José García Armenteros, AMN, ms. 135, ff. 222-245, ms. 136, ff. 4-28 y ms. 312, ff. 56-68.

22 Alejandro Malaspina, Manila, 29 de julio de 1789, AMN, ms. 1826, ff. 87-91.

R. I., $1999, \mathrm{n}^{\circ} 216$ 
$n a s^{23}$ (1791), con el fin de incluirla luego en lo que debería haber sido su Memoria política, sirviéndose igualmente de lo expresado en el anterior trabajo para sus Reflexiones políticas sobre las Islas Filipinas y Marianas ${ }^{24}$.

En dicho Discurso Armenteros propuso la reanudación del comercio con Joló, Mindano, Borneo, Siam, Camboya, etc., en los que hallarían mercado algunos productos asiáticos, funcionando ocasionalmente como intermediarios o con la venta directa de productos de primera necesidad fabricados en las Islas. Relaciones que serían fructíferas desde el punto de vista económico no sólo por la creación de un nuevo mercado, sino también por los beneficios reportados al no tener que recurrir a las armas para combatir la piratería. Conjuntamente, se apuntaban las ventajas de reanudar las actividades en Ternate y Tidore, en donde los españoles habían mantenido sendos fuertes hasta 1662 como apoyo para el comercio del clavo y cuyos régulos, en 1778, habían solicitado al gobernador de Filipinas su vuelta para librarse de la opresión ejercida por los holandeses. Por su parte, ambas islas carecían ya de los preciados árboles de especias, destruidos bajo coacción holandesa para impedir la competencia en su mercado, pero en su lugar era posible vender a sus habitantes géneros de la India y distintos productos alimenticios, mientras el clavo podía obtenerse de algunas de las islas de las Molucas no sometida a los holandeses y transportarlo luego a las Filipinas donde se suponía podría aclimatarse ${ }^{25}$.

Con diferente tono, tanto por el motivo de sus estudios como por su peculiar carácter, pues terminó siendo expulsado de las Islas debido a su cooperación con González Carvajal -mecenas suyo desde su llegada en 1783 -, el médico, botánico y siempre polémico, Francisco Noroña (ca. 1748-1788) inspeccionó algunos parajes de los alrededores de Manila describiendo plantas útiles o poco conocidas. Asimismo, González Carvajal le encargó que preparase una colección de maderas útiles para la construcción de navíos, de edificios y para el comercio, con el objeto de enviarla al ministro José de Gálvez ${ }^{26}$. En octubre de 1784, también bajo la protección del director de la sociedad, comenzó la elaboración de una Historia Natural de Filipinas donde el naturalista pretendió realizar un minucioso examen de los reinos vegetal, animal y mineral; obra que quedó inconclusa debido a su precipitada marcha hacia Batavia tras el enfrentamiento que se produjo con el gobernador Basco y Vargas. En el momento de su salida, Noroña llevaba ejecutadas la «descripción de trescientas especies distintas de plantas, con

\footnotetext{
23 José García Armenteros, AMN, ms. 621, ff. 110-169 v․

24 Juan PIMENTEL, La física de la monarquía. Ciencia y política en el pensamiento colonial de Alejandro Malaspina (1754-1810), Madrid - Aranjuez, Doce Calles - CSIC, 1998, pp. 318 y ss.

25 Díaz-Trechuelo Spinola, M.L. (1963), Op. cit., pp.467-470.

26 Consulta de González Carvajal a J. Gálvez, Manila, 20 de julio de 1785, AGI, Filipinas, leg. $691, \mathrm{n}^{\circ} 26$
}

R. I., $1999, \mathrm{n}^{\circ} 216$ 
mas de 30 generos nuevos desconocidos en la Botanica, que igualmente hice dibujar y sacar à lo natural» ${ }^{27}$.

Por encargo de la Sociedad escribió también: Método de criar los gusanos de seda $^{28}$ y Disertacion instructiva sobre la canela, y el methodo de cultivarla, como se practica en Ceylán ${ }^{29}$. Aun antes de redactar la primera disertación comenzaron los problemas con el gobernador, de modo que una vez terminada fue retenida para su traducción a los idiomas castellano, tagalo, pampango y visayo, siendo finalmente retirada a consecuencia de la publicación, en noviembre de ese mismo año, de la Ynstruccion hecha por el gobernador, y Capitan General de estas Islas, en que hace vér á sus Moradores, la importancia del plantio y beneficio de las Moreras, y cria del gusano de seda ${ }^{30}$. Como consecuencia de sus desavenencias con la autoridad, González Carvajal —que tanto interés tuvo por desbancar de ese comercio a los chinos, por lo que llegó a trasladar todas las moreras plantadas en la hacienda de los agustinos, a extramuros, a Malate, en las proximidades de donde se reunía la Sociedad-, no se atrevió a remitir la memoria de Noroña al gobernador, temiendo que entrase en celos con su autor, ya que según el director de la Sociedad ${ }^{31}$ la diferencia entre ambas disertaciones era notable, inclinándose a favor de la del naturalista. En una carta al ministro Gálvez, González Carvajal se lamentaba de «No poder dar à la prensa esta instrucción; porque à màs de los celos, y desazones que acarrearía su publicidad, habría tales embarazos con el Oidor Fiscal, y la Audiencia, que jamás permitirian su impresión ${ }^{32}$, de todas formas, terminó por distribuirla por las provincias a espaldas del gobernador. El abismo entre ambas personalidades creció con el tiempo. En principio, se impidió que Noroña entrase a formar parte de la plantilla de Hacienda y, más tarde, se le prohibió ejercer la medicina, su única fuente de recursos, por lo que finalmente decidió partir hacia Batavia al tiempo que elevaba sus quejas a la Corte española. Nunca más volvió a las Islas, dando comienzo a una exploración que le llevó desde Java a las islas de Mauricio y Madagascar.

Es evidente que existe una continuidad entre los estudios que para la Sociedad escribió Noroña y los que elaboró Juan de Cuéllar ${ }^{33}$ (ca. 1739-1801) para la

27 Carta de Francisco Noroña, Manila, 21 de marzo de 1786, AGI, Filipinas, leg. 904, no 82 urgente.

28 Francisco Noroña, Manila, 25 de septiembre de 1785, AGI, Filipinas, leg. $691, \mathrm{n}^{\circ} 70$ bis.

29 Francisco Noroña, Manila, 20 de enero de 1786, AGI, Filipinas, leg. 904, n. 82.

30 José Basco y Vargas, Manila, 28 de noviembre de 1785, AGI, Filipinas, leg. 691, n 70 bis.

31 Consulta de González Carvajal a J.Gálvez, Manila, 20 de julio de 1785, AGI, Filipinas, leg. 691. $\mathrm{n}^{\mathrm{o}} 26$.

32 Consulta de González Carvajal a J. Gálvez, Manila, 20 de diciembre de 1785. Carta sobre el estado del cultivo de moreras, AGI, Filipinas, leg. 691. doc. 70 bis.

33 B. BAÑAs Llanos, Don Juan de Cuéllar y sus comisiones científicas en Filipinas, (17391801), Madrid, Tesis Doctoral, Universidad Complutense de Madrid, 1991, (inédita); F. de las BARRAS DE ARAGÓN, «El botánico Juan de Cuéllar y sus trabajos en Filipinas a fines del s. XVIII», Asociación Española para el Progreso de la Ciencias, Sevilla. Ciencias Naturales, 1917ª t. II, pp. 
Real Compañía de Filipinas, cuya erección tuvo lugar en $1785^{34}$, con objeto de la explotación comercial de las Islas. Cronológicamente, Cuéllar arribó a Filipinas cinco meses después de la salida de Noroña, es decir, el 9 de agosto de 1786; a nivel profesional, Cuéllar se diferencia del anterior por haber sido nombrado «oficialmente» para el cargo de botánico, a pesar de que no se le dotase de sueldo alguno, siendo sus trabajos continuación de los de sus antecesores. Sus funciones fueron dirigir y fomentar de manera eficaz las producciones objeto del comercio de la Compañía, lo que antes había perseguido la Sociedad, si bien Cuéllar centró sus actividades en impulsar los cultivos de morera y canela, bastante extendidos a su llegada a las Islas, gracias, entre otros, a la labor de Francisco Xavier Salgado ${ }^{35}$.

Al igual que había ocurrido con la Sociedad Económica, la Real Compañía de Filipinas topó con la hostilidad del Consulado que lo acusó de ejercer una comercio exclusivista a su favor, culpándole del declive que en esos momentos estaba sufriendo el comercio en general, cuyas causas fueron únicamente coincidentes en el tiempo con la erección de la Compañía.

Aunque entre las actividades de Cuéllar se contemplaba llevar a cabo diversos ensayos de introducción, así como la potenciación de otros ya iniciados como el de la canela, éstos, por su propio carácter, entraron en contradicción con los fines puramente pragmáticos de la Compañía que perseguía beneficios inmediatos. Por esa misma razón, aunque Cuéllar, al igual que los naturalistas que trabajaron para la Sociedad, logró algunas mejoras en los cultivos de pimienta, azúcar, sibucao, añil, y en la elaboración de los tejidos de algodón, esas tímidas mejoras no estuvieron a la altura de lo esperado por la Real Compañía que lo destituyó en 1795. Asimismo, Cuéllar colaboró con los naturalistas de la expedición Malaspina a su paso por las Islas y contribuyó en gran medida al conocimiento natural del Archipiélago filipino por parte de España gracias a los numerosos envíos de plantas, dibujos y otros objetos que fueron destinados al enriquecimiento del Real Gabinete de Historia Natural y al Real Jardín Botánico de Madrid.

Con relación a la introducción y al cultivo de la canela, su final fue similar al de los ensayos realizados con otras especias en diversas colonias del Índico, como, por ejemplo, con el caso del clavo y la nuez moscada en Isla de Francia. Tanto en uno caso como en el otro, la introducción de especias ocupó un lugar

\footnotetext{
97-111; F. de las BARRAS DE ARAGÓN, Varios trabajos del botánico D. Juan del Cuéllar, enviado a Filipinas en el siglo XVIII, recolectados en el Archivo de Indias de Sevilla. Sevilla, 1931; F. de las BARRAS DE ARAGÓN, (1948), «Los naturalistas españoles en Filipinas hasta fines del siglo XVIII», Letras Colombianas, XIII, nº 4, Madrid, 1948, pp. 879-895, y Mª. P. SAN Pío, (coord.), La Expedición de Juan de Cuellar a Filipinas, Madrid, Lunwerg-CSIC, 1998.

34 M.L. Díaz-Trechuelo SPINOla, La Real Compañía de Filipinas. E.E.H.A, Sevilla, 1965.

35 Sobre los estudios que desarrolló Salgado durante sus largos años en las Islas, puede consultarse: F. de las BARRAS DE ARAGÓN, «Don Francisco Xavier Salgado y sus obras en Filipinas en el siglo XVIII», Asociación Española para el Progreso de la Ciencias, Sevilla, Ciencias Naturales, t. II, 1971b, pp. 53-70.
}

R. I., 1999, n. ${ }^{\circ} 216$ 
preponderante en el relanzamiento de la economía colonial, pues, supuestamente, debía librarlos del monopolio económico que ejercían las potencias que controlaban su mercado, pero en ningún caso se obtuvieron los resultados esperados ${ }^{36}$.

\section{EL CUERPO DE INGENIEROS. INICIOS DE UNA CONCIENCIA CONSERVACIONISTA Y DEL CONCEPTO DE EXPLOTACIÓN CONTROLADA}

Antes de concretar la labor que efectuaron los ingenieros de montes en las Filipinas - lo que supone un salto temporal de algo más de medio siglo-, cabe mencionar que el desarrollo de los estudios florísticos del Archipiélago no se apartó mucho de lo que se ha descrito hasta este momento, es decir, fueron los religiosos los que dedicaron su tiempo a tales menesteres, con las debidas excepciones antes señaladas y los trabajos de los naturalistas de la expedición dirigida por Alejandro Malaspina: Pineda, Née y Haenke. De cualquier modo, entre los primeros sobresalió la obra del padre Manuel Blanco (1778-1845), Flora de Filipinas, editada por primera vez en 1837. En ella son patentes sus limitaciones tanto en lo relativo a las áreas geográficas como a las zonas altitudinales abarcadas, así como en la validez de las identificaciones realizadas, lo que no le resta valor al ser el primer estudio florístico filipino elaborado conforme al sistema sexual linneano ${ }^{37}$.

Continuando con nuestra secuencia, el Cuerpo de Ingenieros de Montes se creó con el objeto de conservar y explotar racionalmente los montes peninsulares y de ultramar. Sus orígenes se remontan a la fundación en 1848 de la primera Escuela Especial de Ingenieros de Montes en la localidad de Villaviciosa de Odón, provincia de Madrid ${ }^{38}$. Dicha escuela fue promovida por un pequeño grupo de ilustrados vinculados al Jardín Botánico de Madrid y a la Sociedad Económica Matritense, entre los que destacaron las figuras del abogado Bernardo de la Torre Rojas (1792-1875), quien asumió funciones más acordes con su profe-

36 En relación al comercio de la canela, véase: A. GARCíA-ABÁSOLO, «Efectos de las Expediciones Científicas en Filipinas», A.R. DíEZ ToRre, T. MALlo y D. PACHECo FERnÁNDEZ, (coord.). De la Ciencia Ilustrada a la Ciencia Romántica, Actas de las II Jornadas sobre «España y las expediciones científicas en América y Filipinas», Madrid, Ateneo de Madrid-Doce Calles, 1994, pp. 7387, ver pp. 75-77.

37 Véase entre otros: V. Mendoza PASCuAl, Estudio de la obra del padre Manuel Blanco «Flora de Filipinas» y su Vigencia en la actualidad, Madrid, Tesis, Universidad Complutense de Madrid, 1994, (inédita). E.D.C. MERRILL, A Review of the Identification of the Species described in Blanco's Flora of Filipinas, Manila, Bureau of Public Printing 1905; E.D.C. MERRILL, Species Blancoanae. A Critical Revision of the Philippine Species of Plants described by Blanco and by Llanos, Manila, Bureau of Printing, 1918, y F.M. VELKAMP, «A Note on Philippine Collections of F.M. Blanco and A. Llanos». Blumea, 10(2) 1989, pp. 143-145.

38 P. GARCía EsCUdERo y P. FERNÁNDEZ DE URRUTIA, La Escuela Especial y el Cuerpo de Ingenieros de Montes. Los cien primeros años de su existencia (1848-1948), Madrid, 1948. 
sión durante la erección de la Escuela y la de Agustín Pascual González (1818$1884)^{39}$, discípulo del matemático José María Vallejo y del botánico Antonio Sandalio de Arias, que fue pensionado entre 1840 y 1842, conjuntamente con Esteban Boutelou, en Tharant (Sajonia), localidad donde se fundó en 1811 bajo la dirección de Heinrich Cotta la escuela forestal más influyente de Alemania. De allí trajo consigo la Dasonomía, nueva disciplina científica surgida de la evolución sufrida por los estudios de silvicultura desde finales del siglo XVIII, instaurándola en España como primer profesor de la Escuela de Ingenieros de Montes. Algo más tarde, en 1853 se erigió definitivamente el Cuerpo de Ingenieros de Montes en torno igualmente de la figura de Agustín Pascual.

Los principios de la dasonomía giraron alrededor de la explotación racional y la conservación de los bosques, defendiendo con este objeto la permanencia de las tierras forestales bajo la tutela del Estado, con lo que se mantenían lejos de la rapiña privada, al tiempo que se hacía especial hincapié en la fuerte influencia física que mostraban los bosques en la conservación del equilibrio climático, hidrológico, edáfico, etc. Dicha base teórica condicionó la actuación de los ingenieros de montes españoles, quienes ejercieron una fuerte oposición al proceso de Desamortización en la Península, si bien es cierto que en las Filipinas apoyaron justamente el proceso contrario como única forma de potenciar el desarrollo agrícola, pues, como antes dijimos, a excepción de los latifundios religiosos, no se logró generar una clase de propietarios rurales, ni tan siquiera tras la creación en 1881 de la Comisión Especial de Ventas y Composiciones de Terrenos Baldíos y Realengos ${ }^{40}$. A finales del siglo la situación no había cambiado significativamente.

Poco tiempo después de crearse por real decreto del 20 de mayo de 1863 el Ministerio de Ultramar, a fin de englobar todos los asuntos relativos a las colonias con excepción de los despachos de Estado, Guerra y Marina y tras su división en las secciones del Consejo de Ultramar de Cuba, Puerto Rico, Filipinas y Norte de África, se establecieron las inspecciones generales facultativas de Ultramar, entre ellas la de Montes, la cual permaneció inoperativa hasta 1867 coincidiendo con la fundación de la Junta Central de Agricultura, Industria y Comercio y de un nuevo intento de relanzar la economía colonial. Sobre este último punto hay que señalar el desplazamiento de la industria de construcción naval desde el astillero de La Habana, en declive desde finales del siglo XVIII, hacia las Islas, en donde aún se hallaba abundante materia prima y mano de obra bara$\mathrm{ta}^{41}$; al mismo tiempo, se promulgaban diversas medidas destinadas a potenciar el comercio con Filipinas, como fueron la habilitación de puertos para las actividades exportadoras e importadoras (1855), ofreciendo facilidades a los extranjeros

39 L. OlaZÁBAL, «D. Agustín Pascual», Revista de Montes, 9, 1885, pp. 33-50.

40 Véase sobre este punto: V. CASALS COSTA, [1], pp. 368-369.

41 G. de ARANDA, [8], pp. 21-22, y A. FernÁnDEZ DE CASTRo, La comisión especial de Ventas y Composiciones de terrenos baldíos y realengos de Filipinas, Revista de Montes, 10, 1886, pp. 481-489.

R. I., 1999, n. $^{\circ} 216$ 
para realizar operaciones comerciales y, en 1869, la modificación de las tarifas arancelarias con la apertura del canal de Suez.

Además de la Inspección General, cuyo objetivo principal fue controlar la producción de los montes, se constituyeron dos Jefaturas de Distrito, la Comisión de la Flora y Estadística Forestal, así como un Jardín Botánico en Manila. El programa de actuación pergueñado por los ingenieros puede consultarse en la Memoria de 1874 elaborada por su primer director Sebastián Vidal y $\operatorname{Soler}^{42}$ y concretada en los siguientes puntos por su sucesor en el cargo, Ramón Jordana ${ }^{43}$ : 1.- elaboración de una estadística de las existencias y producciones de los montes; 2.- clasificación de los mismos; 3.- deslinde de la propiedad forestal; 4.- elaboración de un plan de aprovechamiento, y 5.- conservación de los bosques en esos momentos en manos del Estado y los restantes mientras no se procediera a su venta ${ }^{44}$.

Hasta la llegada del Cuerpo de Ingenieros la visión de las riquezas florística del archipiélago resultaba bastante idílica, o así lo dejaban traslucir las palabras del naturalista Haenke: «[el clima] (...) en conjunto favorece hasta tal punto la vegetación y la frondosidad que no es fácil encontrar nada semejante en ninguna parte de la tierra. Lo mismo hay montes de ásperas cumbres como vastas llanuras, llenas de selvas vírgenes, repletas de árboles abundantes, majestuosos y, al parecer, en su mayor parte desconocidos. Éstos suelen ofrecer frutos silvestres, que constituyen alimentos completos y suficientes para las naciones salvajes que vagan por todas partes (...) Como en ninguna otra parte, encontramos abundantes

42 Vidal y Soler (1842-1889) se licenció como ingeniero en 1865, siendo más tarde profesor de la Escuela de Montes; en 1871 pasó a las Filipinas para hacerse cargo de la Inspección de Montes y luego de la Comisión de la Flora y del Jardín Botánico de Manila. Gracias a sus herborizaciones, en la actualidad se conservan en el Jardín Botánico de Madrid un herbario de 50.000 ejemplares recolectados durante su estancia en las Islas. Del mismo modo, realizó una importante labor de divulgación, contribuyendo a que la comunidad científica internacional conociera la flora del archipiélago, a través de la participación en diversas exposiciones universales como fueron las celebradas en París (1867), Filadelfia (1876), Amsterdam (1883) y Madrid (1887).

Entre sus obras destaca: Sinópsis de familias y géneros de plantas leñosas de Filipinas. Introducción a la flora forestal del archipiélago filipino (1884); Reseña de la flora del archipiélago filipino (1883); Comisión de la Flora Forestal de Filipinas. Revisión de las plantas vasculares filipinas (1886) y Phanerogamae Cumingianae Philippinarum (1886); y desde el punto de vista forestal se han de citar: «El clima de Filipinas» y «Breve descripción de algunas maderas más importantes y mejor conocidas del archipiélago filipino», ambas publicadas en 1874 en el volumen 7 de la Revista de Montes y la Memoria sobre el ramo de montes de las Islas Filipinas (1886).

43 El segundo director de la Inspección, Ramón Jordana y Morera (1839-1900) también se formó como ingeniero en Madrid (1859), ejerciendo luego como profesor de la Escuela. Trabajó en la Comisión del Mapa Forestal Peninsular, dirigiendo posteriormente la Inspección de Montes filipina entre 1873 y 1885 . Entre sus obras destacan: Guía del viajero de Barcelona a Manila por el canal de Suez (1886); La inmigración china en Filipinas (1888); Memorias sobre la producción de los montes públicos de Filipinas, años 73-74, 74-75 y 75-76; y Bosquejo geográfico e históriconatural del archipiélago filipino (1885).

44 R. JORDANA, Memoria sobre la producción de los montes públicos de Filipinas durante el año económico de 1873-74, Madrid, 1876, pp. 8-9. 
maderas para todo género de construcciones. También hallamos plantas medicinales desconocidas y abundantes remedios específicos que son habituales para los indígenas» ${ }^{45}$.

Comparativamente era verdad que los bosques filipinos se encontraban mejor conservados que, por ejemplo, los cubanos, donde el proceso de deforestación había sido mucho más intenso y temprano, de modo que para el año 1874 Jordana calculaba en un $70 \%$ la superficie aún ocupada por montes ${ }^{46}$. Del mismo modo, por primera vez se admitió el gran desconocimiento que se tenía de las Filipinas en su conjunto, donde aún no habían sido sometidas a la Corona grandes extensiones tanto de la isla de Mindanao, la de Paragua y la de Joló, el dominio era únicamente costero en las de Samar y Mindoro e inclusive se desconocían tierras en Luzón, en el área de la contracosta del Pacífico y en la extensa cordillera del Caraballo en la provincia de Isabela y Cagayán, así como en los distritos de Infanta y Príncipe. Según los cálculos, la actuación de los forestales quedaba reducida a los 9 millones de hectáreas susceptibles de explotación de los 19.405.915 de hectáreas boscosas incluidas en la superficie total de las islas, mensurada en 27.732.995 hectáreas en las que se incluía Mindanao, Balabac y las Calamianes, pero no las islas de Paragua ni las que componen el archipiélago de Joló, las Batanes, Marianas, Carolinas y Palaos. Cifra exagerada según Fernández de Castro, pues la escasez de personal había impedido realizar una clasificación siquiera aproximada de la totalidad de los montes, de forma que debían tratarse de cálculos deducidos ${ }^{47}$.

En realidad, tampoco el estado de conservación de los bosques era el que se esperaba. «Que los montes filipinos no son inagotables lo proclaman, no sólo la fisiología vegetal, cuyas leyes invariables en todas las regiones, climas y países nos enseñan que la formación y desarrollo de los árboles maderables es siempre obra de un largo período de años, y que esa obra puede ser completamente aniquilada si una codiciosa impaciencia induce al hombre á empuñar el hacha destructora, sino también la experiencia, que en no pocas localidades del mismo Archipiélago nos muestra ya cuán funestos son los efectos de las cortas persistentes y de las talas abusivas» ${ }^{48}$. La explotación continuada para fines agrícolas, para la obtención de combustible y los abusos en las cortas para la construcción de navíos o para el comercio maderero, habían alcanzado con dureza las perife-

45 HAENKE, Regnum Vegetabile Insularum Philippicarum, manuscrito traducido por V.Ibáñez en V. IвÁÑEZ, Trabajos científicos y correspondencia de Tadeo Haenke, Barcelona, LunwergMinisterio de Defensa, 1993. La cita pertenece a V. IBÁÑEZ, «Filipinas, paraíso vegetal al otro lado del mundo». A.R. DíEZ Torre, T. MALlo, y D. PACHECo FernándeZ, (coord.), [36], p. 62.

46 R. JORDANA, [44], p. 119

47 A. FERnÁNDEZ DE CASTRO, «Los montes de Filipinas», Revista de Montes, 11, 1887, pp. 417422, 476-482, 494-499, 601-603, ver pp. 419-420.

48 R. JORDANA, «El comercio de maderas en Filipinas», Revista de Montes, 13, 1889, pp. 129136, 153-159, 186-195; cita en p. 129.

\section{R. I., 1999, n. $^{\circ} 216$}


rias de las grandes zonas pobladas, así como algunas costas y los bosques de ribera. Según Vidal ya únicamente era posible hallar el molave, el narra, el calantás y otros árboles de maderas apreciables para la construcción «en sitios donde el hacha del maderero no haya penetrado» ${ }^{49}$. No sólo la Marina Mercante campeaba a sus anchas, cuando algún particular se proponía construir un buque, elegía como astillero un sitio próximo a los montes, solicitando del Gobierno Superior Civil o de los Jefes de Provincia licencia para el aprovechamiento de madera sin necesidad de precisar el número de árboles, su especie, dimensiones, fechas, ni plazos para la ejecución de la obra, de modo que si «se calculasen escrupulosamente los daños que estos particulares causan a los montes, el valor de las maderas que emplean en la construcción de sus buques y el de los que cargan en los mismos, se vería que el Estado le tendría más cuenta construir los buques y luego regalárseles a los interesados» ${ }^{50}$.

Refería Bosch también que se habían cortado 1.500 .000 árboles maderables de los bosques públicos filipinos entre el 1 de septiembre de 1863 y el 31 de agosto de 1864, sin que el Estado se reembolsase nada a cambio. Así, solamente en el puerto de Manila se hallaban matriculados 7.356 barcos que suponían unas 187.758 toneladas de madera, sin contar con las embarcaciones fluviales de las que casi todas las familias poseían una; bancas hechas con 4 o 6 troncos de 10-15 metros de diámetro, de las que salían a la venta el 13 de diciembre en el mercado de Sexmoan unas 500 o 600 bancas nuevas. Además, había que sumar a dicho gasto los provocados durante el proceso de tala y su transporte, de modo que donde se había cortado una pieza para una banca de primera, un centenar de árboles quedaban destrozados. A este respecto, en 1866 el Gobierno Superior Civil de Filipinas tuvo que limitar las cortas en determinadas áreas afectadas por talas abusivas, como fue el caso de la provincia de Tabayas, la isla de Burias y la de Mindoro, a las que se añadieron en 1874 las de Cebú y Bohól, acotándose desde el mar y las márgenes fluviales hasta dos leguas al interior.

Al contrario de lo que sucedía en Europa, en Filipinas era raro encontrar rodales puros de una especie determinada, a excepción de las provincias del norte de Luzón, por lo que no se pudo adoptar los señalamientos en pie como se hacía en España, siendo preciso recorrer grandes extensiones para marcar unos centenares de árboles de calidad, de modo que los madereros precisaban explotar distintos puntos de una misma costa para completar sus cargamentos y cuando se agotaban las buenas maderas las zonas quedaban aún cubiertas de arbolado pero empobrecidas en calidad y diversidad. Bosch señalaba la desaparición de masas boscosas en las provincias próximas a Manila, entre otras: Cavite, Bataan, Pam-

\footnotetext{
49 S. VIDAL, «Botánica y productos forestales», El Globo, Madrid, 1887, pp. 17-22, cita en p. 18.

50 M. BosCh Y JULIÁ, «Rápida ojeada sobre el estado de los montes de Canarias, Puerto Rico, Cuba y Filipinas». Revista de Montes, 1, 1868, pp. 169-188, 329-341, 396-413, 465-479, cita en pp. 401-402.
} 
panga, Laguna, etc., donde también se cortaba indiscriminadamente para leña, procediendo conjuntamente a la propagación de los manglares lo que llevaba al estrechamiento de los alvéolos de los ríos y esteros, dificultando la navegación y favoreciendo los desbordamientos e inundaciones.

Jerárquicamente, las islas de mayor riqueza forestal del Archipiélago filipino eran: la isla de Luzón, así mismo la de mayor extensión, en donde se encontraban extensas masas forestales al norte entre la sierra de Caraballo y la sierra Madre en la costa oriental, al oeste la sierra de Zambales y al sur las de las provincias de Tayabas, que por sí sola producía la tercera parte de los rendimientos totales, las Camarines, principalmente las vertientes del seno de Ragay y Guinayangán. Les seguía en extensión la isla de Mindanao, de la que se desconocía su riqueza forestal por la falta de comunicaciones y lo belicoso de sus gentes. Lo mismo sucedía con Paragua y con el interior de Mindoro, aunque sus costas se explotaban desde hacía muchos años, siendo en 1893 la primera provincia por sus ingresos al Estado de productos de madera. La isla de Catanduanes era también rica en número y calidad de sus maderas, pero la falta de comunicaciones entre ellas y lo peligroso de la navegación en sus costas redujo su explotación. Ricas eran también las islas de Samar y Masbate, mientras en el resto de las islas el terreno poblado de monte alto iba desapareciendo conforme se acrecentaban los cultivos agrícolas y las roturaciones arbitrarias ${ }^{51}$. Otros puntos de Luzón muy explotados fueron Nueva Ecija, Bulacan, Zambales; del mismo modo se habían destruido millones de árboles en las provincias Visayas, en la isla de Negros, debido al gran desarrollo agrícola de los últimos diez años y también en las islas de Marinduque, Tablas, Sibuyan, Ticao, Panay, Leite y Samar ${ }^{52}$.

Los aprovechamientos de los montes del Estado eran de tres clases: de pago, gratuitos y fraudulentos. En los de pago, que comprendían las maderas destinadas al comercio, los productos gomoresinosos, las leñas para la exportación y para el interior de las islas, el procedimiento se limitaba a la expedición de una licencia por la Dirección General de Administración Civil, previo informe de la Inspección de Montes, en la que se hacía constar las provincias en que se iban a realizar los aprovechamientos, aunque no la localización precisa, ni el procedimiento, quedando obligados a dar aviso al funcionario del ramo más próximo, cuando tuviera hecho un acopio de cierta importancia y desease embarcarlo o utilizar las maderas en la misma localidad, para satisfacer los derechos, tras los cuales podían disponer de las maderas. Como medida de mejora Fernández de Castro planteaba la posibilidad de ensayar el marcado de las piezas cortadas. Para ello, no sólo sería necesario realizar una relación de los encargados en cada localidad

51 S. CERÓN, «Memoria sobre la producción de los montes públicos de Filipinas y servicios practicados durante el año de 1891», Revista de Montes, 17, 1893, pp. 329-338, 359-365, 451-457, 481-487, ver pp. 330-331.

52 M. BosCh y Juliá, [50], pp. 400-403. A. Fernández de CASTRo, [47], pp. 495-496.

\section{R. I., 1999, n. $^{\circ} 216$}


de las cortas, sino fijar las localizaciones y los puntos de embarcación. Con cierta periodicidad, se marcarían los troncos en los lugares de acopio, dando orden de ingreso por el valor de los derechos correspondientes a cada medición, de esta forma al efectuar la descarga se podría comprobar si las maderas venían marcadas o no ${ }^{53}$. Los problemas se hallaban en la escasez de personal facultativo y auxiliar, la falta de medios de comunicación y de seguridad, lo que no permitían llevar a cabo los trabajos preliminares de reconocimiento y marcado; tampoco había la posibilidad de fijar la cantidad y clase de las maderas objeto del aprovechamiento en grandes cantidades, ni de realizar grandes acopios de determinadas clases de maderas. Además, dicho método hacía fácil el fraude de muy diversas maneras: $1^{\circ}$ por el fraude de aquellos árboles derribados y no transportados; $2^{\circ}$ por aquéllos transportados y luego abandonados, pues era suficiente con declarar que no les pertenecían para no pagar; $3^{\circ}$ por la confusión a la hora de asumir la responsabilidad entre los encargados en cada punto de las cortas y $4^{\circ}$ por lo extenso del territorio que impedía una buena vigilancia de las costas. A esto último había que añadir otras prácticas fraudulentas como los caingins, de los que luego hablaremos y las que se realizaban en las regiones ocupadas por razas no dominadas.

Los aprovechamientos gratuitos comprendían dos clases: las maderas para construcción y los de leña, estacas y productos secundarios. Los primeros constituían aprovechamientos de importancia, cuya tasación era más elevada que los ingresos obtenidos por el Estado debido a la inexactitud en la remisión de los partes trimestrales que exigía el art. 81 del Reglamento. Así, por los datos obtenidos, Cerón aseguraba que el aprovechamiento gratuito de los pueblos en madera debía sobrepasar los 300.000 pesos, que a una media de 3 céntimos de peso por pie cúbico hacían unos 8.300 .000 pies cúbicos. Madera que, según él, no era utilizada por los pobres indígenas, que no usaban maderas, al menos de calidad, para construir sus chozas y bancas, por lo que era imprescindible prohibir que pudieran ser objetos de comercio. Del mismo modo, debían regularse las extracciones para leñas, también de carácter gratuito, puesto que maderas raras de alto valor para el Estado, podía sacarse gratis en trozos de dos metros como leña ${ }^{54}$.

Los datos de la Inspección de Montes respecto a la producción anual de los montes públicos en Filipinas entre 1871 y 1886 mostraban un progresivo incremento en la producción, a excepción de los años económicos del 1871 al 1881 y del 1882 y 1883 , como consecuencia principalmente de diversos desastres naturales. Más grave, porque se trató de un error de cálculo humano, era el descenso observado durante el año económico 1886-87, cuando por ahorrar el sueldo de 26 monteros de un total de 52 suprimidos del Servicio de Inspección, que venía a suponer 7.599 pesos anuales, se habían perdido, debido al fraude, unos 14.881,43 pesos en producción. Medidas, las de limitación de efectivos, que no sólo impe-

53 A. FERnÁNDEZ de CASTRO, [47], pp. 476-478.

54 S. CERÓN, [51], pp. 335-338. 
dían ensayar el sistema de marcado, sino que iban incrementando el fraude al Estado 55 .

A esta sobrexplotación hubo que añadirle las desacertadas prácticas agrícolas de roza, como las conocidas por cainges o caingins, realizadas indiscriminadamente sobre todo tipo de suelos por los indígenas, desconocedores de métodos más modernos y de que el valor de lo destruido superaba con creces los rendimientos obtenidos. Tras las rozas el arbolado no se recuperaba jamás: «Vastas extensiones de la isla [Mindanao] y en general todas aquellas cuyo arbolado ha sido pasto de las llamas del «caingue», forman los cogonales. El cogon no es una sola planta, sino muchas afines (gramíneas, cyperáceas y algunas juncáceas), que presentan un parecido en su porte, que las hace comprender en una denominación común; las especies del género Saccharum abundan en ellos. Hay cogon bajo, regular pasto, y cogon alto o carrizal del que ninguna utilidad se saca; sirve sólo para oponer dificultades al cultivo y hasta considerables a las comunicaciones ${ }^{56}$. Si se realizaba en terrenos pendientes, los daños eran mayores porque las tierras removidas eran arrastradas por las aguas a los sitios bajos, desapareciendo la capa vegetal y quedando la roca al descubierto o la tierra estéril de la parte inferior; así junto a la esquilmación del bosque se había destruido el medio de sujetar las tierras y las aguas, produciéndose grandes torrentes en la época de lluvias que arrasaban y abatían cuanto se encontraban a su paso, cegando el cauce de los ríos y produciendo grandes inundaciones en las vegas y los valles. Diversas fueron las causas que impidieron su persecución. Por un lado, el que generalmente se realizaran en sitios alejados de los pueblos, en fondos o en el centro de los bosques, de difícil control; por otro lado, se quejaban los ingenieros de que había autoridades que no apoyaban sus acciones sino las dificultaban por la creencia de que era el único modo de extender el cultivo agrario y de que los pobres pudieran conseguir el arroz para su sustento. Razón por lo que se incrementaban en aquellos años en los que la sequía había sido seguida por la aparición de la langosta, años en los que los caingins eran la única manera de conseguir tierras donde sembrar arroz o camote para sobrevivir. Además, el reglamento vigente sólo contemplaba la compra al Estado como medio de obtener la propiedad de los terrenos baldíos, medida inútil para atraer a los llanos a la gente del interior, por lo que se creía necesario permitirles realizar sus caingins en los futuros terrenos de cultivo, alrededor de los sitios señalados para constituir los pueblos. A este respecto, Sáinz de Baranda se atrevía a proponer se ordenase a la Inspección la designación y deslinde de los terrenos baldíos realengos, que podían luego concederse para establecer poblaciones nuevas o para su repartición entre los indígenas que se fueran

55 A. Fernández de CAStro, [47], pp. 479-482, 601-603 y A.D.R., «Servicio de Montes en las Islas Filipinas». Revista de Montes, 11, 1885, pp. 433-439, 455-467.

56 La descripción de la vegetación de Mindanao a la que pertenece este fragmento puede verse en: G. ARANDA, [8], p. 23

R. I., $1999, \mathrm{n}^{\circ} 216$ 
presentando; sistema que no produciría ingresos a la Hacienda Pública puesto que la cesión sería gratuita, pero evitaría la competencia por los terrenos solicitados en venta, ya que los primeros carecían de valor por su lejanía de los núcleos poblados, condiciones no deseables por aquéllos que querían comprar ${ }^{57}$.

En marzo de 1882 comenzó a funcionar la Comisión Especial de Venta y Composiciones de Terrenos y el 26 de diciembre de 1884 un real decreto encomendaba las composiciones a las Juntas Locales y Provinciales. Entre 1881-82 y 1884-85, progresivamente fueron aumentando el número de expedientes despachados, al igual que los ingresos conseguidos por el Tesoro, pero con posterioridad a ese año, se observó una disminución en el número de expedientes procesados, debido a que la Inspección necesitaba clasificar las instancias de composición que obraban en su poder y formar estados para remitirlos a los Jefes Provinciales y que de allí pasasen a las Juntas Locales y Provinciales según el citado decreto, para que finalmente fuesen estas últimas las encargadas de tramitarlos. Los datos conocidos correspondientes al año económico 1885-86 mostraban un considerable descenso en el total de títulos despachados desde que la Inspección fue retirada, aunque más tarde volvió a asumir dicha función para las fincas mayores de 30 hectáreas o de menor cabida, colindantes con terrenos baldíos del Estado ${ }^{58}$.

Resumiendo, Vidal señalaba que la zona agrícola, la más poblada y la mejor conocida, estaba ocupada por plantas introducidas por el hombre, entre las que se encontraban el arroz, el maíz, la caña de azúcar, el algodonero, el tabaco, el cafeto, el cacao, distintos árboles frutales americanos y asiáticos, etc., mientras la vegetación propia del país podía hallarse solamente en los parajes no abiertos por el agricultor ${ }^{59}$. Por el momento, tampoco parecía factible pensar en una política de repoblación, más aun sin contar con el apoyo del clero: «El estado de retraso en el que se encuentra el país no permite pensar siquiera en repoblaciones artificiales o vedas que produzcan con el tiempo la repoblación natural en las zonas forestales; pero quizá en algunas leguas comunales, cuando ocurra que los párrocos no sean refractarios, sino aficionados al arbolado, no será tan difícil conseguir plantaciones de molave, ipil, tindalo, banana, narra y demás especies maderables de reconocida importancia y aplicación» 60 .

Obviamente uno de los objetivos que se marcaron los ingenieros fue el inventariado de la riqueza forestal del Archipiélago, para cuyo fin se creó por Real Decreto del 21 de julio de 1876 una Comisión de la Flora Forestal Filipina que no se constituyó hasta el 1 de mayo de 1878 por estar Sebastián Vidal y Soler, su director, en la Exposición Universal de Filadelfia. De corta vida, ya que fue su-

57 J. SÁINZ DE BARANDA, «Memoria sobre la producción de los montes públicos de Filipinas y servicios realizados por la Inspección General del Ramo en el año económico 1885-1886». Revista de Montes, 11, 1887, pp. 263-270. 300-307, 343-347, 366-375, 399-407, ver pp. 343-347.

58 S. CERÓn, [51], p. 361 y FERNÁNDEZ DE CASTRO, [47], pp. 479-482.

59 S. VIDAL, [49], p. 18.

60 J. SÁINZ DE BARANDA, [57], pp. 400-401. 
primida en 1886, durante su período de actividad se reunieron un total de 2060 ejemplares de plantas, que fueron identificadas con la ayuda del entonces director de Kew Dr. Rolfe y publicadas en la Revisión de plantas vasculares de Filipinas (1886), obra que fue completada con el listado del Catálogo de las plantas del herbario recolectado por el personal de la suprimida Comisión de la Flora Forestal (1892). Con motivo de la Exposición Universal de Madrid, al comentar la labor efectuada por los ingenieros, Vidal reconoció las limitaciones del trabajo realizado hasta ese momento, la escasez de los datos obtenidos sobre determinadas áreas y, no sin sorna, hizo referencia a aquellos botánicos que se acercaban a las Islas en busca de especies nuevas. Así pues, nos comentaba que con motivo de la Inspección de Montes se había elaborado un mapa de vegetación en dos hojas, más uno nuevo para la presente exposición. En ellos quedaba señalada la extensión ocupada por las zonas agrícolas y forestales, separándose esta última «en parte explorada y en parte en una «terra incognita»; de donde tanto se desconoce, ya aprendemos á no esperar colecciones «completas», tengamos esto bien presente cuando las califiquemos de «ricas», y no se envidie el naturalista los hallazgos anteriores, pues no tiene más que encaminarse á las comarcas «verdeoscuras» del mapa, y se le promete que ha de tener ocasiones para «bautizar» especies nuevas, y con relativa facilidad pasará su nombre al «almanaque de santones» y gozará del privilegio de que, mejor ó peor abreviado, quede como autoridad de los «latines» de su cosecha» ${ }^{6}$.

En los últimos años de administración española la situación no había mejorado mucho. Salvador Cerón, al cargo de la Inspección en 1893, reconocía la imposibilidad de atajar los aprovechamientos ilícitos por falta de personal y medios económicos, así como el nulo cambio en las prácticas agrícolas y en la propiedad territorial ${ }^{62}$. De igual manera, tampoco se había logrado llevar a efecto una política de repoblación y muchas localidades estaban ya seriamente afectadas. En 1887, con motivo de la exposición universal que se celebró en Madrid, Vidal confesaba que aunque en ella se daba debida cuenta de «los tesoros que encierran aquellos montes y de los cuidados que su gestión merece. Sentimos, sin embargo, no hallar algo que á repoblaciones se refiera pues sabemos cómo se han agotado ya las buenas maderas en muchas comarcas y cuán desnudas están ya las sierras de Ilocos y Zambales, de Cebú y parte de Panay» ${ }^{63}$.

En conclusión, tanto los esfuerzos de la Sociedad Económica como los de la Real Compañía Filipina durante el último cuarto del siglo XVIII, así como la labor llevada a cabo por el Cuerpo de Ingenieros de Montes en las islas Filipinas en la segunda mitad del XIX, resultaron del todo infructuosos, no por falta de interés en las riquezas naturales del Archipiélago, tanto desde el punto de vista

61 S. VIDAL, [49], p. 20.

62 S. CERÓN, [51], pp. 333-334 y 338.

63 S. VIDAL, [49], p. 22. 
económico como puramente ecológico, sino por la continuación de formas económicas desfasadas y perjudiciales, como fueron el falso sostén del Galeón, desavenencias institucionales y personales, el latifundismo, las malas técnicas agrícolas o el desacertado comercio maderero, entre otros motivos como consecuencia del fuerte recorte en las ayudas con las que estas instituciones debieron contar, tanto en lo que respecta al personal necesario como en recursos económicos.

It has been my intention to analyze the role of the economic societes and the Cuerpo de Ingenieros de Montes in relation with the rational use of the Philippine's forests, since the last quarter of the $18^{\text {th }}$ century until the end of the Spanish administration.

From a commercial point of view lacking any conservationist awareness, the necessity of a rational use of the forests will be obvious for the forestry experts along the $19^{\text {th }}$ century, but because of the survival of outdated practises and a scarce institutional support on economic and staff matters their conservationist efforts were fruitless. 